\title{
A Criança Entra em Cuidados Paliativos: O Sentimento do Cuidador Principal Frente
} à Notícia

The Child in Palliative Care: The Feeling of the Main Caregiver's Front of the News

\section{El Niño Entra en Cuidados Paliativos: El Sentimiento del Cuidador Principal}

Ante la Noticia

Layanne Crystina Bandeira Nunes ${ }^{1}$

Arli Diniz Oliveira Melo Pedrosa ${ }^{2}$

Adriana de Andrade Barbosa ${ }^{3}$

Hélio Monteiro Júnior ${ }^{4}$

Lucas de Mello Ferraz ${ }^{5}$

\section{Resumo}

Objetivo: identificar qual foi o sentimento e as emoções do cuidador principal de crianças em cuidados paliativos, em acompanhamento no serviço de oncologia pediátrica do Instituto de Medicina Integral Professor Fernando Figueira (IMIP), no momento em que foram comunicados que a criança encontrava-se fora de possibilidades terapêuticas de cura. Método: Estudo descritivo, com abordagem qualitativa, a amostra foi composta por 8 cuidadores principais de crianças em cuidados paliativos acompanhadas no referido serviço. A coleta de dados foi realizada por meio de entrevista gravada, no período entre janeiro e maio de 2012. Para a análise dos dados empregou-se como referencial a análise de conteúdo de Bardin. Resultados: houve a predominância da mãe como cuidadora principal destas crianças, foi possível identificar em suas falas temas

${ }^{1}$ Enfermeira pela Faculdade de Medicina da Universidade Federal de Alagoas. Especialista em Gestão em Saúde. Autora correspondente: Av. Menino Marcelo, no 5585, Residencial Parque Maceió, torre 1, apt. 1505, Antares. CEP 57083-410. Maceió - AL. Brasil. E-mail: layannecbn@gmail.com ${ }^{2}$ Psicóloga. Mestre em Gestão Hospitalar.

${ }^{3}$ Enfermeira. Residência em Saúde da Criança.

${ }^{4}$ Bibliotecário. Especialista em Literatura Infanto Juvenil.

${ }^{5}$ Graduando em Enfermagem no Centro Universitário CESMAC.

Recebido: Nov/2016 - Aceito: Jan/2017. 
recorrentes como: esperança, fé, espiritualidade, medo, mudanças no estilo de vida e na situação familiar, tristeza, impotência, aceitação e negação da situação de saúde da criança. Conclusão: constata-se que os Cuidados Paliativos, apesar de propor uma política de acrescentar qualidade de vida aos dias, não confortam essas mães que veem nessa condição a imagem da finitude dos seus filhos, que vê ameaçada a sua qualidade de mãe.

\section{Descritores: Cuidados Paliativos; Cuidado da Criança; Mães; Cuidadores.}

\section{Abstract}

Objective: identify what was the feeling and emotions of the main caregiver of children in palliative care in monitoring the pediatric oncology unit of the Instituto de Medicina Integral Professor Fernando Figueira (IMIP), when they were reported that the child was out of therapeutic healing. Method: descriptive study with a qualitative approach, the sample was composed of 8 main caregivers of children in palliative care together in that service. Data collection was conducted through interviews recorded, the period between January to May 2012. For data analysis we used as reference the content analysis Bardin. Results: showed that there was a predominance of the mother as primary caregiver of these children, it was possible to identify recurring themes in their speeches as: hope, faith, spirituality, fear, changes in lifestyle and family situation, sadness, helplessness, denial and acceptance health status of the child. Conclusion: Thus it appears that palliative care, despite proposing a policy of adding quality of life to days, not comfort those mothers who see this condition the image of the finiteness of their children, who threatened their quality of mother.

\section{Descriptors: Hospice Care; Child Care; Mothers; Caregivers.}

\section{Resumen}

Objetivo: identificar cual fue el sentimiento y las emociones del cuidador principal de los niños en cuidados paliativos en acompañamiento en el servicio de oncología pediátrica del Instituto de Medicina Integral Professor Fernando Figueira (IMIP), en el momento en que se informó que el niño estaba fuera de sus posibilidades terapéuticas de cura. Método: estudio descriptivo con enfoque cualitativo, la 
muestra constituyó en 8 cuidadores principales de los niños en los cuidados paliativos juntos al referido servicio. La recolección de datos se realizó a través de entrevista grabada entre enero $y$ mayo de 2012. Se basó para el análisis de datos como referencial el análisis de contenido de Bardin. Resultados: hubo un predominio de la madre como cuidadora principal de estos niños, fue posible identificar en sus recurrentes líneas temas como: la esperanza, la fe, la espiritualidad, el miedo, los cambios en el estilo de vida y la situación familiar, la tristeza, la impotencia, la aceptación y el rechazo de la situación de salud del niño. Conclusión: Se observa que los cuidados paliativos, a pesar de proponer una política añadir calidad de vida a los días, no confortan a esas madres que ven en esta condición la imagen de finitud de sus hijos, que amenazaba sus calidades de madre.

\section{Descriptores: Cuidados paliativos;}

Cuidado de niños; Madres; Cuidadores.

\section{Introdução}

O câncer infanto-juvenil compreende todos os casos de câncer que acometem crianças e adolescentes até os 18 anos de idade. É um evento considerado raro, cerca de $2 \%$ a $3 \%$ do total dos cânceres que acometem a população $^{(1-2)}$, entretanto representa a primeira causa de morte por doença nesta faixa etária ${ }^{(2)}$.

Grandes e notórios foram os avanços no tratamento do câncer infantil, tanto do ponto de vista diagnóstico como terapêutico ${ }^{(2)}$. Porém, quando se encontram esgotadas as possibilidades terapêuticas de cura disponíveis, dá-se então início a um processo onde o cuidar é priorizado: os cuidados paliativos.

Cicely Saunders dedicou-se ao estudo da dor e alívio dos sintomas dos pacientes terminais e na década de 1970, juntamente com Elisabeth Klüber-Ross, instituíram o Movimento Hospice nos Estados Unidos ${ }^{(3)}$. No Brasil, O Cuidado Paliativo iniciou-se na década de 1980 e cresceu significativamente a partir do ano 2000 , com a criação de novos serviços e a consolidação dos já existentes ${ }^{(3)}$.

A Organização Mundial de Saúde (OMS) define cuidado paliativo como "uma abordagem que promove a qualidade de vida dos pacientes e suas famílias, que enfrentam doenças que ameacem a continuidade da vida, através da prevenção e do alívio do sofrimento"(4:3). 
Elizabeth Klüber-Ross pesquisou sobre as concepções de morte e do morrer em pacientes terminais e que este passa por cinco estágios para compreender a finitude humana, que são: negação, raiva, barganha, depressão e $\operatorname{aceitação~}^{(5)}$.

No estágio da negação, o paciente tende a não aceitar a sua condição, é transitória e logo substituída por uma aceitação parcial. Na fase da raiva a negação é substituída pelo sentimentos de revolta, raiva e ressentimento. $\mathrm{O}$ estágio da barganha tende a ser mais calmo, ao pedir a Deus por um prolongamento de vida, ou pelo menos por alguns dias sem dor ou sofrimento físico. A depressão surge quando o paciente não pode mais negar e esconder a sua doença e pode ser caracterizada em duas fases: a depressão por uma perda passada e a depressão por conta da perda iminente. $\mathrm{O}$ estágio da aceitação acontece quando um paciente que tiver recebido alguma forma de ajuda para superar todas as fases anteriores e tiver tempo suficiente para isto, não obstante atingirá um estágio em que não sentirá mais raiva ou depressão quanto ao seu "destino", se trata quase de uma fuga de sentimentos, o término da luta, é quando é chegado o momento do repouso ${ }^{(5)}$.
Estes estágios também podem ser experienciados pelas pessoas próximas, que convivem com os pacientes em fase terminal, como os familiares e os cuidadores principais e os profissionais de saúde.

A criança com câncer e em cuidados paliativos gera uma modificação em todo o contexto domiciliar e requer uma reorganização da estrutura familiar. A família e a criança enfrentam problemas relacionados com a doença e o seu tratamento, como períodos de hospitalização, reinternações, efeitos adversos da terapêutica, afastamento dos membros da família, modificações das atividades diárias, angústia, dor, sofrimento e o medo constante da possibilidade de morte ${ }^{(6)}$.

O cuidador principal acompanha todo o sofrimento e dificuldades da criança. Além de compartilhar do sofrimento ainda experimenta os sentimentos de dúvida, de desamparo, as angústias e os medos e ainda precisam assumir o seu papel de colaborador em todas as etapas do processo que, em muitos casos, é longo ${ }^{(7-8)}$.

Quem acompanha todo o decurso da enfermidade da criança, desde o momento do diagnóstico, o tratamento e suas complicações e intercorrências até 
o momento do desfecho final, seja a vida ou a morte, é a mãe ${ }^{(9)}$, para ela é essencial sentir que está atendendo as demandas do filho durante o processo, que está desempenhando satisfatoriamente o seu papel de boa mãe.

Os cuidados paliativos encaram a morte como um processo normal, sem adiá-la nem prolongá-la, oferece o alívio da dor e de outros sintomas, afirmam a vida e proporciona suporte para que o paciente possa viver o mais ativamente possível, além de ajudar a família e cuidadores no processo de luto $^{(10)}$, portanto deve ser instituídos de preferencia desde o momento do diagnóstico de uma doença ameaçadora à vida, sendo complementar ao tratamento curativo $^{(11)}$.

É preciso que a criança saiba o que está acontecendo consigo e com o seu corpo, para que possa se preparar da melhor forma possível para esta nova circunstância de vida. E garantir, sempre, o que é mandatório na filosofia dos cuidados paliativos: acrescentar qualidade aos dias. Quando o curar já não é mais possível, o cuidar deve ser redobrado.

\section{Método}

com abordagem qualitativa, visto que esta faz referência a estudos de significados, percepções, experiências de vida, e aborda mecanismos de adaptação, cuidados e papéis de cuidadores profissionais e familiares ${ }^{(12)}$. Foi desenvolvido na unidade de Oncologia Pediátrica do Instituto de Medicina Integral Professor Fernando Figueira (IMIP).

A amostra foi composta pelos cuidadores principais das crianças em cuidados paliativos do IMIP que retornaram para a consulta ambulatorial ou que estavam internados durante o período da coleta de dados. A coleta de dados foi realizada após a aprovação do projeto de pesquisa pelo Comitê de Ética e Pesquisa do IMIP, no período de janeiro a maio de 2012, obedecendo todos os aspectos éticos e legais para o estudo envolvendo seres humanos, de acordo com a Resolução no . 196/96 ${ }^{(13)}$.

Para coleta de dados utilizou-se a entrevista semi-estruturada e utilizou-se as seguintes questões norteadoras: Poderia me falar o que você sentiu no momento em que recebeu a notícia de que a sua criança não teria mais possibilidades de ser curada, que ela entraria em cuidados paliativos?; Poderia me contar qual o seu sentimento hoje em relação a sua criança?; O que 
esta situação mudou na sua vida desde que a sua criança entrou em cuidados paliativos?.

A entrevista foi gravada e transcrita na íntegra no mesmo dia em que foi realizada, buscando manter todas as inferências e as emoções do cuidador. O anonimato foi preservado, os entrevistados foram identificados por nomes de pedras preciosas como forma de traduzir a força e o imensurável valor dessas pessoas diante desta delicada situação.

Para análise dos dados utilizou-se a análise de conteúdo de Bardin, que é considerada uma técnica de pesquisa que trabalha com a palavra e permite que se produzam deduções do conteúdo da forma de comunicação e expressão do sujeito ${ }^{(14)}$.

Não houve apoio financeiro e material recebido para $\mathrm{o}$ desenvolvimento da pesquisa, bem custos aos sujeitos da pesquisa de qualquer natureza.

\section{Resultados}

Fé, espiritualidade, esperança, medo, mudanças no estilo de vida e na situação familiar, tristeza, impotência, aceitação e negação da situação de saúde da criança foram temas recorrentes nas falas dos sujeitos da pesquisa. Um misto de sentimentos que se traduzem na essência do ser humano, do ser que cuida, do ser que sente e sofre.

No quadro 01 observa-se o perfil dos cuidadores principais, onde $62,5 \%$ das entrevistadas declararam ser casadas, $87,5 \%$ afirmou ser do lar, a renda familiar apresentou variações entre 01 e 04 salários mínimos.

A faixa etária das crianças variou entre 04 e 15 anos de idade. A idade das mães compreende as faixas etárias de 29 a 50 anos, média de 36,6 anos, considerada uma faixa etária relativamente jovem, em se tratando das dificuldades advindas do acompanhamento do filho com câncer. Ressaltamos também que $100 \%$ das entrevistadas têm outros filhos, o que também contribui para elevar a sobrecarga de sentimentos e preocupações que permeiam o universo da família com uma criança portadora de uma doença grave.

O tempo em que as crianças encontram-se em cuidados paliativos mostrou-se relativamente curto, variando entre 08 dias e 01 ano, apesar do longo período de tratamento da doença. 
Tabela 01 - Caracterização Geral dos Cuidadores Principais das Crianças em Cuidados Paliativos com Nomes de Pedras Preciosas.

\begin{tabular}{|c|c|c|c|c|c|c|c|c|}
\hline $\begin{array}{l}\text { Sujeito/ } \\
\text { Dados }\end{array}$ & Ametista & Cristal & Esmeralda & Diamante & Quartzo & Rubi & Safira & Jade \\
\hline $\begin{array}{l}\text { Estado } \\
\text { Civil }\end{array}$ & casada & casada & casada & casada & $\begin{array}{l}\text { união } \\
\text { estável }\end{array}$ & casada & $\begin{array}{l}\text { união } \\
\text { estável }\end{array}$ & $\begin{array}{l}\text { união } \\
\text { estável }\end{array}$ \\
\hline Ocupação & professora & do lar & do lar & do lar & do lar & do lar & do lar & do lar \\
\hline Renda & 03 & 01 & 01 & 01 & 02 & 04 & 01 & 01 \\
\hline Idade & 36 & 30 & 42 & 50 & 29 & 31 & 39 & 36 \\
\hline Parentesco & mãe & mãe & mãe & mãe & mãe & mãe & mãe & mãe \\
\hline $\mathrm{N}^{\circ}$ filhos & 03 & 02 & 03 & 07 & 03 & 03 & 03 & 02 \\
\hline $\begin{array}{l}\text { Idade da } \\
\text { Criança }\end{array}$ & 14 & 06 & 14 & 12 & 09 & 04 & 08 & 15 \\
\hline $\begin{array}{l}\text { Tempo } \\
\text { Cuidado } \\
\text { Paliativo }\end{array}$ & 02 meses & 15 dias & $\begin{array}{l}\text { cerca de } 01 \\
\text { ano }\end{array}$ & 06 meses & 03 meses & 08 dias & 15 dias & $\begin{array}{l}\text { cerca de } \\
01 \text { ano }\end{array}$ \\
\hline
\end{tabular}

A partir da análise do conteúdo das entrevistas, extraiu-se 04 categorias, a saber: $\mathrm{O}$ sentimento predominante no recebimento da notícia; A esperança; A mãe como cuidadora; Cuidados paliativos e modificações pessoais e na vida familiar.

\section{Discussão}

A representação do câncer infantil vai além da destruição da dimensão física e psicológica da criança, mas, sobremaneira, na dimensão da sistemática familiar, tendo em vista que, o diagnóstico afeta toda a estrutura da família, que passa a viver em função da criança adoentada e da patologia ${ }^{(15)}$.

A mãe é a figura que acompanha a criança em todas as fases do processo de tratamento $^{(9)}$ e isto demonstra a qualidade da mulher como cuidadora, corroborada em outros estudos que envolvem cuidadores principais e/ou familiares $^{(16-17)}$.

\section{O Sentimento Predominante no}

\section{Recebimento da Notícia}

O sentimento experimentado no momento em que receberam a notícia que a sua criança encontrava-se fora de possibilidades terapêuticas de cura traduzem um misto dos mais diversos sentimentos. Emoções que revelam a complexidade do vínculo mãe-filho, relatos que demonstram tristeza, dor e sofrimento, mas que também traduzem amor e fé:

Ai Jesus, naquela hora não achei, não achei nem chão, fiquei muito abalada na hora [...] na minha mente assim pra mim que ele ia ficar bom, tudo, mas de repente receber essa notícia assim que ele não ia mais ter cura, foi um choque mesmo, mas ai tá nas mãos de Deus, seja feita a vontade Dele. Eu senti ali que eu tinha perdido meu filho já na hora né? (Safira). 
Estudos apontam que "a mãe precisa buscar apoio na fé, em 'algo' que transcenda suas forças e o apoio das pessoas, pois tem consciência das suas limitações e fraquezas, para que não desista"(18:305).

A diversidade de sentimentos expressos nos remete aos 05 estágios fundamentais experimentados e que permeiam a finitude humana. Foi possível identificar nas falas das mães os estágios descritos por Klüber-Ross:

... Na hora que eu recebi essa notícia eu fiquei abalada, mas hoje eu olhando assim pra ele, pra mim ele não tá com essa doença, tá entendendo? Eu olhando ele assim, eu não quero acreditar que ele tá com essa doença não, que não tem cura... (Safira).

Essa negação pode ser fruto do turbilhão de novos sentimentos, dos pensamentos acerca da doença grave, da mudança do seu papel de mãe de uma criança saudável, para tornar-se cuidadora de uma criança com câncer, em cuidados paliativos.

A fase da raiva advinda da incredulidade devido ao insucesso do tratamento é observada no seguinte relato:

Até hoje mesmo eu num consigo, num me conformo né?! Por essa doença ser tão agressiva, tantos anos de tratamento e sempre ela ser mais forte do que os remédios... (Jade).
No estágio da barganha, é muito forte a questão da espiritualidade e a referência a Deus, podemos inferir isto nos relatos da espera dessa mãe por um milagre de Deus:

...nós mães a gente fica esperando
que Deus faça um milagre nos nossos
filhos, mesmo sabendo [...] que Deus
possa levar a qualquer momento, mas
a gente fica rezando, eu, na minha
situação, fico rezando, pedindo a
Deus que Deus faça um milagre, que
faça o meu filho ficar bom... (Rubi).

A Depressão pode vir cercada de um sentimento de tristeza, angústia, medo e até culpa. A depressão também pode ser traduzida e percebida como uma forma de contrariedade e aborrecimento pela situação vivenciada:

... eu vi ela com saúde, ai quando ela teve essa recaída ai eu fiquei assim desgostosa ne?! [...] mas eu ainda tenho esse desgosto, não mudei nada de desgosto, ainda tenho, ainda penso muito, ainda choro de ver minha filha num estado daquele, que eu vi ela, ela não enxerga mais, ela não caminha e ela já caminhou ne?! Antes de ter essa recaída ela caminhou, ela enxergava e agora ela não tá vendo, não tá vendo mais... (Diamante).

Já na fala de Esmeralda podemos destacar um tom de aceitação da condição de sua criança, que se encontra em cuidados paliativos há cerca de 01 ano, percebe-se também as emoções vivenciadas no momento da 
notícia e a tristeza que faz parte do seu cotidiano até o momento atual:

Eu agradeci muito a Deus por Deus ter dado mais um ano de vida, ele completou 14 anos domingo. E foi assim uma felicidade pra mim, pelo que ele passou, pelo que vi e sei, me sinto mais confiante [...] Tem horas que eu quero até desmoronar, assim, mas depois pego a pensar direitinho e eu me sinto assim mais confortável de saber o problema de tudo né? (Esmeralda).

Este relato ainda nos remete a um ponto fundamental: a comunicação efetiva entre profissionais de saúde, família e paciente, que, direta ou indiretamente, auxilia na compreensão e aceitação de maneira mais concreta e eficaz. Porém mais importante do que transmitir a realidade dos fatos é maneira de se fazer isto.

\section{A Esperança}

Esperança: sentimento que permeia todo o universo da mãe cuidadora, que diariamente travam uma batalha nesta luta incansável contra o câncer, a doença tão ameaçadora para a vida de seus filhos, geradora de tantos medos e conflitos. E, apesar de tudo, há ainda a esperança, a esperança de que este não seja o fim:

Meu sentimento é que Deus me dê força pra lutar até o fim e que eu espero que esse não seja o fim, né?!
Que pras médicas pode até ser, né?! Mas pra Deus não (Cristal).

Essa é fundamentalmente a base que fortalece essas mães: o sentimento de fé aliado à esperança. Estudos apontam que o apoio recíproco entre as mães, a troca de experiências, a autoestima transmitida e o consolo também constituem elementos que auxiliam no enfrentamento das circunstâncias geradas pela doença e no fortalecimento da mãe ${ }^{(18)}$.

\section{A Mãe como Cuidadora}

A mãe é quem frequentemente assume o cuidado da criança na situação de doença e é identificada como a principal fonte de apoio ${ }^{(19)}$. Para a mãe é fundamental transmitir força e segurança para o seu filho ${ }^{(18)}$, e sente que ela é a melhor pessoa para estar ao seu lado, é quem pode dar carinho, conforto e a segurança de que ele precisa, destacando o seu lado protetor.

...Tem que deixar tudo pra cuidar [...] mudou tudo, é hospital, deixa casa, deixa os outros filhos deixa marido, deixa tudo né?! pra ficar só aqui, por que eu acho que agora, nesse momento, ele que precisa mais de mim assim né?! Os outros precisam, mas ele precisa mais, jamais, eu nunca deixo ele não, enquanto eu tiver força 'to' lutando (Safira). 
Cuidar de uma criança com câncer pode gerar conflitos internos e esta cuidadora está passando por um dos momentos mais difíceis de sua vida e neste cuidado estão envolvidos vários sentimentos como o de impotência, medo, ansiedade da separação, incredulidade e culpa ${ }^{(20)}$. Pois "ser mãe de uma criança com câncer é viver uma experiência mediada pela construção de um novo papel, permeado pelo seu dever, pelo tempo como mãe que está ameaçado pela doença, pelo significado que ela atribui ao câncer"(18).

\section{Cuidados Paliativos e Modificações Pessoais e na Vida Familiar}

A rotina de uma mãe cuidadora de uma criança com câncer e em cuidados paliativos pode modificar-se completamente e estas modificações advindas desse novo tipo de tratamento, voltado para o cuidar, para as necessidades crescentes da criança associado ao conhecimento de que a criança não será curada, que a morte, mais do que nunca, é uma certeza, modifica o modo de viver e de ver a vida e principalmente modifica a essência do ser cuidador, do ser mãe.

... mudou muita coisa em mim. Não tenho mais aquela vontade de ser como eu era. Quando eu vejo ele alegre tem hora de eu tá alegre também. Eu podendo ver meu filho tão alegre e amanhã ou depois acontecer alguma coisa, ai mudou assim. Não sou mais aquela que eu era (Esmeralda).

Estudos apontam que no sistema familiar os momentos de maior desequilíbrio são evidenciados em determinadas fases, que podem estar relacionadas às fases da doença ou aos marcos do desenvolvimento infantil ${ }^{(6)}$.

Já no relato de Ametista, mãe de um adolescente de 14 anos em tratamento desde os 02 anos de idade e em cuidados paliativos há 02 meses, observamos uma serenidade ao falar do assunto, ela nos diz que as modificações maiores ocorreram após a última recidiva, por ter comprometido a qualidade de vida da criança:

Não, não mudou muita coisa não, de jeito nenhum, assim o que, o que tá mudando, não quando ele entrou em cuidados paliativos, mas quando ele teve essa piora [...] Pesa muito a questão de deixar a família, passar muito tempo aqui, toda essa turbulência... (Ametista).

É possível verificar que no dia-adia da assistência aos pacientes com câncer e seus familiares, essa experiência é muito complexa e sofrida, não se limita apenas na doença em si. $\mathrm{O}$ contato com outras pessoas que também passam por uma situação de vida 
semelhante são elementos-chave para a compreensão psicossocial do câncer ${ }^{(21)}$.

\section{Conclusão}

Com esta pesquisa pudemos evidenciar, e por que não dizer experimentar, uma gota do infinito oceano de emoções vivenciadas por essas mães em seu cotidiano, em seu complexo papel de mãe, mãecuidadora de uma criança com câncer, mãe de outros filhos sadios que também não deixam de necessitar de sua presença, mãe-esposa-mulher que deixa o convívio de seu lar, para dedicar-se quase que exclusivamente ao cuidado de sua criança adoentada.

Ao entrevistar estas mães tão fortes e tão fragilizadas ao mesmo tempo podemos compreender o quão é delicada essa situação. Por mais sofrimento e dor que a doença e tratamento proporcionem para a criança e para a família, nada é capaz de subtrair o desejo imenso de uma mãe de ter de volta a sua vida, sua rotina na companhia da família que ela tão amorosamente constituiu.

Os cuidados paliativos, apesar de propor uma política de acrescentar qualidade de vida aos dias, não confortam essas mães que veem nessa condição a imagem da finitude dos seus filhos, que vê ameaçada a sua qualidade de mãe. A expectativa de que tudo irá se resolver da melhor forma e a esperança de dias melhores circunda esse tão vasto universo destas mulheres-mães guerreiras, batalhadoras, que não desistem facilmente desta incansável luta.

\section{Referências}

1. Ministério da Saúde (BR). Instituto Nacional de Câncer. Estimativa 2010: incidência de câncer no Brasil / Instituto Nacional de Câncer. Rio de Janeiro: INCA; 2009. Disponível em: http://bvsms.saude.gov.br/bvs/publicac oes/estimativa_2010_incidencia_cance r.pdf.

2. Ministério da Saúde (BR). Instituto Nacional de Câncer. Coordenação de Prevenção e Vigilância de Câncer. Câncer da criança e adolescente no Brasil: dados dos registros de base populacional e de mortalidade. / Institu to Nacional de Câncer. Rio de Janeiro: INCA; 2008. Disponível em: http: //bvsms.saude.gov.br/bvs/publicacoes/c ancer_crianca_adolescente_brasil.pdf.

3. Academia Nacional de Cuidados Paliativos. Manual de Cuidados paliativos. Rio de Janeiro: Diagraphic; $2009 . \quad$ Disponível em: http://www.paliativo.org.br/noticias/201 4/01/manual-de-cuidadospaliativos-anc p-e-liberado-na-biblioteca-virtual/.

4. World Health Organization. Palliative care. Cancer control: knowledge into action: WHO guide for effective programmes; Module 5. Geneva; 2007. Avaliable from: http://www.who.int/cancer/publications/ cancer_control_palliative/en/. 
5. Klüber-Ross E. Sobre a Morte e o Morrer: o que os doentes terminais têm para ensinar a médicos, enfermeiros, religiosos e aos seus próprios parentes. São Paulo: Martins Fontes; 2011; 9.

6. Nascimento LC, Rocha SM, Hayes VH, Lima RAG. Crianças com câncer e suas famílias. Rev Esc Enferm USP. [periódico na Internet]. 2005 [citado 2012 mai. 15];39(4):469-74. Disponível em: http://www.scielo.br/scielo.php?scr $\mathrm{ipt}=$ sci arttext\&pid=S0080-623420050 00400014.

7. Ferreira NMLA, Souza CLB, Stuchi Z. Cuidados Paliativos e Família. Rev. Ciênc. Méd. Medicina (Campinas) [periódico na Internet]. 2008 [citado 2012 mai. 12]; 17(1):33-42. Disponível em: http://periodicos.puc-campinas.edu. $\mathrm{br} /$ seer/index.php/cienciasmedicas/articl e/view/742.

8. Beck ARM, Lopes MHBM. Cuidadores de crianças com câncer: aspectos da vida afetados pela atividade de cuidador. Rev Bras Enferm. Enfermagem (Brasília) [periódico na Internet]. 2007 [citado 2012 jun. 6]; 60(6):670-5. Disponível em: http://www.scielo.br/scielo.php?script $=\mathrm{s}$ ci_arttext\&pid=S0034-7167200700060 0010 .

9. Ortiz MCM. À Margem do leito: a mãe e o câncer infantil. São Paulo: Arte e Ciência; 2003.

10. Melo AGC. Os Cuidados Paliativos no Brasil. Rev. Brasil. Cuidados Paliativos. [periódico na Internet]. 2008 [citado 2012 mai. 4]; 1(1): 5-8. Disponível em: http://www.cuidadospa liativos.com.br/img/din/file/RBCP1.pdf.
11. Costa Filho RC, Costa JLF, Gutierrez FLBR, Mesquita AF. Como Implementar Cuidados Paliativos de Qualidade na Unidade de Terapia Intensiva. Rev. Brasil. Terap. Intens. [periódico na Internet]. 2008 [citado 2012 mai. 4]; 20(1): 88-92. Disponível em: http://www.scielo.br/pdf/rbti/v20n1 /a14v20n1.pdf.

12. Nogueira-Martins MCF, Bogus CM. Considerações sobre a metodologia qualitativa como recurso para o estudo das ações de humanização em saúde. Saúde e Sociedade. [periódico na Internet]. 2004 [citado 2012 jun. 6]; 13(3): 44-57. Disponível em: http://www.scielo.br/scielo.php?pid $=\mathrm{S} 0104-12902004000300006 \&$ script $=\mathrm{s}$ ci_abstract\&tlng=pt.

13. Ministério da Saúde (BR). Conselho Nacional de Saúde. Resolução 196 de 10 de outubro de 1996. Diretrizes e normas regulamentadoras da pesquisa envolvendo seres humanos. Brasília: Ministério da Saúde; 1996. Disponível em:http://bvsms.saude.gov.br/bvs/saude legis/cns/1996/res0196_10_10_1996.ht $\mathrm{ml}$.

14. Caregnato RCA, Mutti R. Pesquisa qualitativa: análise de discurso versus análise de conteúdo. Texto Contexto Enferm. Enfermagem (Florianópolis) [periódico na Internet]. 2006 [citado 2012 mai.11]; 15(4): 679-84. Disponível em: http://www.scielo.br/ pdf/tce/v15n4/v15n4a17.

15. Coelho JA, Bucher-Maluschke JSNF, Käppler CO, Silva SSC. A Família na Perspectiva de País de Filhos com Câncer e de Filhos Sadios. R. Interam. Psicol. [periódico na Internet]. 2010 [citado 2012 mai. 14]; 44(3): 5339. Disponível em: http://www.redalyc. org/pdf/284/28420658016.pdf. 
16. Silva TCO, Barros VF, Hora EC. Experiência de ser um Cuidador Familiar no Câncer Infantil. Rev Rene. (Fortaleza) [periódico na Internet]. 2011 [citado 2012 jun. 14]; 12(3):526-31. Disponível em: http://www.revistarene. ufc.br/vol12n3_pdf/a11v12n3.pdf.

17. Beck ARM, Lopes MHBM. Tensão devido ao papel de cuidador entre cuidadores de crianças com câncer. Rev Bras Enferm. Enfermagem (Brasília) [periódico na Internet]. 2007 [citado 2012 mai. 23]; 60(5): 513-8. Disponível em: http://www.scielo.br/scielo.php?scri $\mathrm{pt}=$ sci_arttext\&pid=S0034-7167200700 0500006 .

18. Angelo M, Moreira PL, Rodrigues LMA. Incertezas diante do Câncer Infantil: Compreendendo as Necessidades da Mãe. Esc Anna Nery Ver. Enferm. Enfermagem [periódico na Internet]. 2010 [citado 2012 mai. 28]; 14 (2): 301-8. Disponível em: http://www.scielo.br/scielo.php?script=s ci_arttext\&pid=S1414-8145201000020 0013 .

19. Moreira PL, Angelo M. Tornar-se Mãe de Criança com Câncer: Construindo a Parentalidade. Rev. Latino-Am. Enfermagem [periódico na Internet]. 2008 [citado 2012 mai. 20]; 16(3): 355-61. Disponível em: http://www.scielo.br/pdf/rlae/v16n3/pt 04.pdf.

20. Grant $\mathrm{CH}$, Traesel ES. Vivências de Cuidadores de Crianças e Adolescentes com Câncer: uma Reflexão sobre o Apoio Psicológico. Disc. Scientia. Série: Ciências da Saúde, Santa Maria. [periódico na Internet]. 2010 [citado 2012 jun. 20]; 11(1): 89108. Disponível em: http://sites.unifra .br/Portals/36/Saude/2010/10.pdf.
21. Menezes CNB, Passareli PM, Drude FS, Santos MA, Valle ERM. Câncer infantil: organização familiar e doença. Rev. Mal-Estar Subj. [periódico na Internet]. 2007 [citado 2012 mai. 10]; 1(8): 191-210. Disponível em: http://pepsic.bvsalud.org/scielo.php?scri $\mathrm{pt}=$ sci_arttext\&pid $=\mathrm{S} 1518$ 61482007000100011. 